\title{
Recent Advances in Nonviral Gene Transfection - A Decade of Research into Poly-( $\beta$-amino esters)
}

\author{
Andreas Zumbuehl\$ \\ §SCS Mettler-Toledo Award Winner (Oral Presentation)
}

\begin{abstract}
The conjugate addition of an amine into a bis-acrylate leads to a linear poly( $\beta$-amino ester). The ease of the reaction and the availability of a wide variety of starting materials, allows the synthesis of large, chemically diverse libraries. Poly( $\beta$-amino esters) condense negatively charged plasmid DNA into nanoparticles that may introduce exogenous genetic information into target cells. After several optimization steps, poly( $\beta$-amino esters) were found that transfect cells as efficiently as an adenovirus. The concept of conjugate addition was also expanded to the synthesis of lipids. These 'lipidoids' were able to efficiently transport small interfering RNA into cells to enable RNA interference therapy in nonhuman primates.
\end{abstract}

Keywords: Cationic lipids · Cationic polymers · Gene therapy · Nonviral gene transfection · RNA interference

Gene therapy has the potential to revolutionize medicine. Unfortunately, this sentence has been written a great many times over the past decades and yet we are still waiting for the safe and efficient treatment of diseases with DNA- or RNA-based drugs.[1] Creating nontoxic and efficient nonviral transfection vectors is one of the important bottle-necks in the field. Over the past years the synthesis of thousands of different poly( $\beta$-amino esters) has given valuable insights into how an optimal vector should look like. This article will trace back the research on poly $(\beta$-amino esters) over the past decade.
In 1999, Robert Langer formulated four design criteria for nonviral gene transfection polymers: They should be made from i) inexpensive and ii) nontoxic monomers iii) bearing cationic moieties iv) that would degrade once they have delivered their cargo. ${ }^{[2]}$ The search started for materials that would meet these criteria. Polyesters were synthesized from activated, $\mathrm{N}$-protected 4-hydroxy-proline showing greatly improved viability of the monkey kidney fibroblast cell-line COS-7 cells over cells treated with the classical, nondegradable poly(ethylene imine) (PEI). [2] The synthesis, however, included a deprotection step, was not atom-economical and limited to few available $\alpha$-amino acids with a secondary amine (primary amines were excluded due to their possible interaction with the polyester).

A solution was found using commercially available bis-secondary amines and letting them react into the Michael-system of a diacrylate (Scheme 1). The reaction proceeded under mild conditions giving polymers between 10,000 and $30,000 \mathrm{M}_{\mathrm{n}}$ and PDI values of around 2 . The poly $\left(\beta^{\mathrm{n}}\right.$ amino esters) were nontoxic to cells and degraded rapidly within two days into diols and bis( $\beta$-amino acids). ${ }^{[3]}$ One of the three polymers reported was found to be particularly insoluble in aqueous buffer; a welcomed feature that allowed the formation of microspheres using a double-emulsion technique. ${ }^{[4]}$ The particles could be loaded with plasmid DNA and would release their payload upon a $\mathrm{pH}$ change trigger, e.g. in macrophages where they could be employed as gene vaccine formulations ${ }^{[4]}$ or degradable particles for paclitaxel delivery. ${ }^{[5]}$

Poly( $\beta$-amino esters) can be synthesized from a wide variety of commercially available diacrylates and amines. Since very little was known about the optimal structure of a DNA vector, a library-approach was chosen: In a first paper, seven different diacrylates were combined with 20 amines giving 140 chemically distinct polymers. ${ }^{[6]}$ Besides the simple sample preparation, a high-thoughput transfection assay had to be developed. The polymers were finally tested in a luciferase plasmid DNA assay in a 96 well plate in quadruplicate. ${ }^{[6]}$ The stage was thus set for a massive, semi-automated synthesis of a library containing 2,350 poly( $\beta$-amino esters). ${ }^{[7]}$ The library was run in DMSO to ease handling of the polymers with the robot and allow direct testing in a cellular assay. The ratio of the amine-containing monomer to DNA phosphate is crucial and has to be optimized for each compound. Therefore, each polymer was run in the three ratios 10:1, 20:1, and 40:1. Generally, polymers with alcohol side-chain were amongst the best performing.

Another important parameter is the molar ratio between amines and diacrylates during the polymer synthesis. This decides if the linear polymer is terminated by an amine or an acrylate group. Two polymers were submitted to an in-depth study and prepared in twelve different molar ratios. ${ }^{[8]}$ The end-group substitution indeed has a tremendous effect on the transfection efficiency and was further analyzed in a separate paper optimizing a 


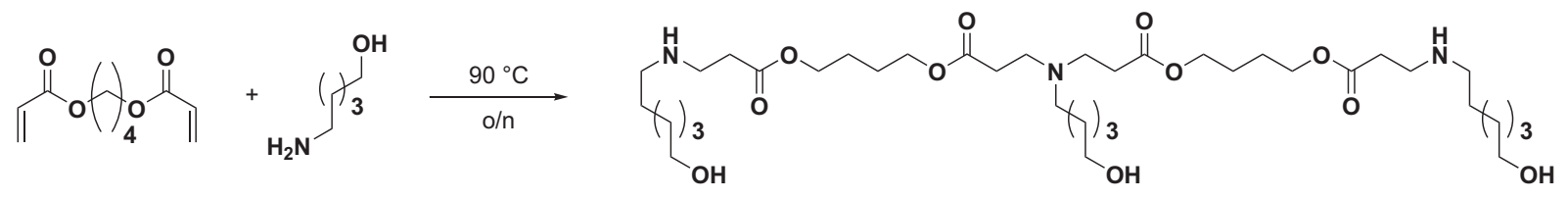

Scheme 1. Synthesis of a poly( $\beta$-amino ester) by the solvent-free reaction of a diacrylate with a bis-secondary amine or a primary amine. Depending on the ratio of diacrylate to amine, the linear polymer is terminated by a secondary amine or by an acrylate group. The depicted polymer was termed C32.

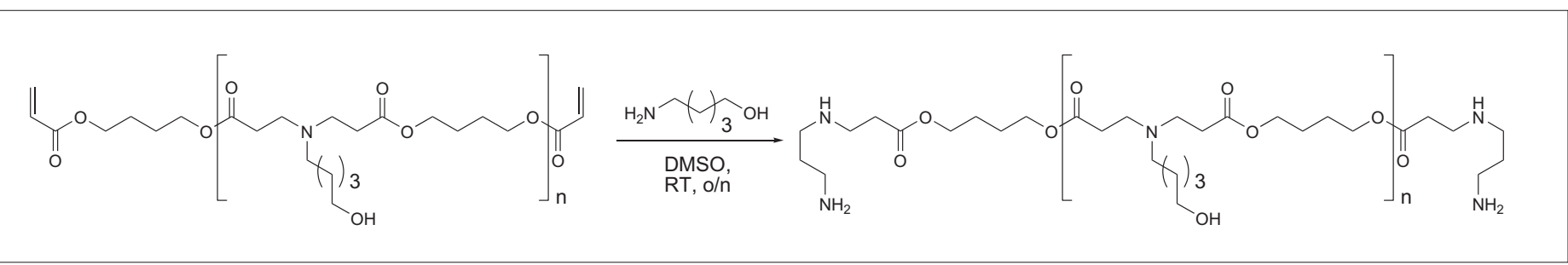

Scheme 2. The poly( $\beta$-amino ester) C32 was synthesized with an excess of 1,4-butanediol diacrylate yielding linear polymers with reactive endgroups. The latter were then substituted with a library of amines.

486 member second-generation library. ${ }^{[9]}$ Generally, a slight excess of amines was preferred (amine to acrylate ratios of 1.025 or 1.050). Of course, changing the ratio also means changing the mean size of the polymer, which is longest at an amine to acrylate ratio of 1.0. An average weight of at least 10,000 Da was needed for efficient transfection. And again it was found that the ideal transfection vector contained an alcohol side-chain paired with a relatively hydrophobic acrylate. The top-performing polymers all complexed DNA into particles with diameters of $70-80 \mathrm{~nm}$.

To further explore the chemistries of poly( $\beta$-amino esters) we decided to leave the internal amines intact (using the optimal 5-amino-1-pentanol) and concentrate on the terminal groups. This time the $\operatorname{poly}(\beta$-amino ester) $\mathrm{C} 32$ was prepared with an excess of 1,4-butanediol diacrylate providing a polymer with reactive end-groups (Scheme 2). ${ }^{[10,11]}$ A library of 37 end-capped poly( $\beta$-amino esters) was synthesized and tested for in vitro and in vivo transfection. Surprisingly, the optimization of the end-capping pushes the efficiency of the vector to unprecedented heights. In fact, a head-to-head comparison between an optimized poly $(\beta$-amino ester) and an adenovirus showed comparable transfections of human umbilical vein endothelial cells. ${ }^{[12]}$ Combined with their low toxicity, members of this latest generation of poly $(\beta$-amino esters) become interesting materials for medicinal applications such as gene transfer to human embryonic stem cells. ${ }^{[13]}$

It occurred to us that the Michael-type reaction between an amine and an acrylate could also be used to access a class of lipidic materials: The reaction of long-tailed acrylates or acrylamides with a library of commercially available amines led to a

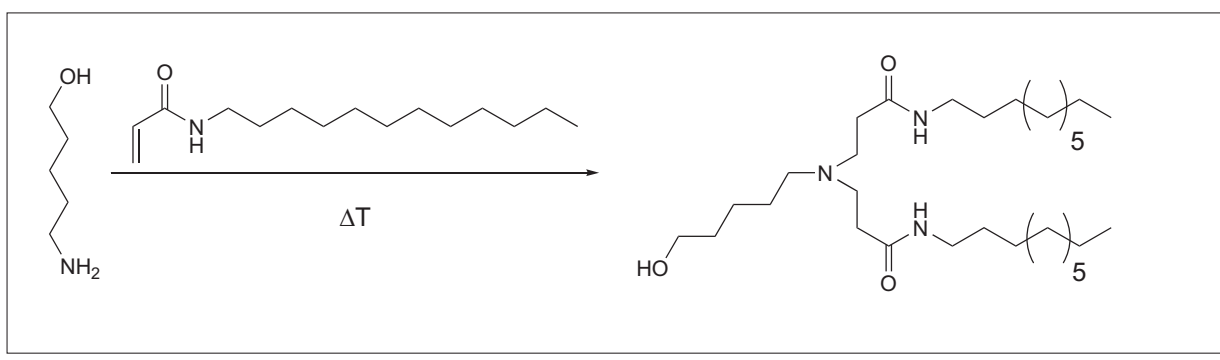

Scheme 3. Synthesis of lipidoids by solvent-free conjugate addition of an amine to an acrylamide or acrylate.

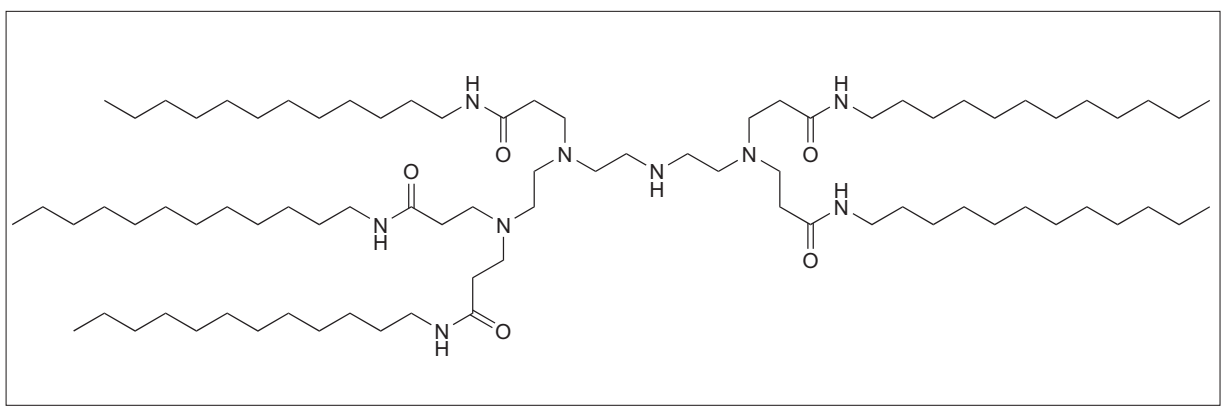

Fig. The most promising lipidoid, $98 \mathrm{~N}_{12}-5$, was tested in various animal models.

library of 1,200 structurally diverse 'lipidoids' (Scheme 3). ${ }^{[14]}$

The lipidoids were tested as siRNA vectors. HeLa cells were stably transfected to express both firefly and Renilla luciferase. Working with siRNA targeting firefly luciferase both the efficiency of the transfection and the toxicity or nonspecific knockdown could be monitored in parallel. Unoptimized, 56 lipidoids mediated equal or better knockdown than one of the premier commercially available transfection agents, Lipofectamine 2000. In collaboration with Alnylam Pharmaceuticals, several of those promising lipidoids were optimized for in vivo RNA interference therapy. The compound $98 \mathrm{~N}_{12}-5$ (amine 98 substituted with 5 equiv. of N-dodeclylacrylamide tails, Fig.) was found to be particularly active and was tested in mice, rats, and nonhuman primates in various disease models. ${ }^{[14]}$

Formulated together with $98 \mathrm{~N}_{12}-5$, cholesterol, and mPEG2000-ceramide $\mathrm{C}_{16}$ an siRNA targeting ApoB-100 showed serum ApoB-100 reduction in cynomolgus monkeys for up to one month after a single bolus i.v. injection. ${ }^{[14]}$ In a similar experiment serum LDL cholesterol levels could be lowered significantly by targeting the 
proprotein convertase subtilisin/kexin type 9 (PCSK9). ${ }^{[15]}$ A pharmacodynamic study on a luciferase-expressing mouse showed the tissue specific RNA interference in the liver.[16]

RNA interference therapy was discovered only recently. Researchers and industry do try not to make the same mistakes again that were made with standard gene therapy. It was therefore taken very seriously when a report noted that the introduction of exogenous short-hairpin RNA using an adenovirus as carrier could oversaturate the cellular microRNA pathways, leading to the death of the studied mice.[17] This report would have meant the end of RNAi therapy before it even began. But, at least with synthetic siRNAs, antagomirs, a thorough study in mouse and hamster liver cells showed effective RNAi-mediated gene silencing without interruption of the endogenous microRNA pathway. ${ }^{[18]}$ Nonviral siRNA vectors seem to be still on track for a promising new medicinal technique.

In conclusion, several libraries of lipidoids and poly( $\beta$-amino esters) were synthesized, each new generation improving the results of the previous library. $\beta$-Amino amide-based materials for RNAi therapy and end-capped poly( $\beta$-amino esters) for pDNA delivery might be one possible solution to finally bring closer the dream of safe and efficient human gene therapy.

\section{Acknowledgments}

The author would like to cordially thank Mettler-Toledo and the Swiss Chemical Society for the SCS-Mettler-Toledo award. A part of the described research was made possible through a Swiss National Science Foundation Postdoctoral Fellowship.

Received: January 14, 2009

[1] N. Somia, I. M. Verma, Nature Rev. Genetics 2000, $1,91$.

[2] D. Putnam, R. Langer, Macromolecules 1999, 32,3658 .

[3] D. M. Lynn, R. Langer, J. Am. Chem. Soc. 2000, 122, 10761

[4] D. M. Lynn, M. M. Amiji, R. Langer, Angew. Chem., Int. Ed. 2001, 40, 1707.

[5] A. Potineni, D. M. Lynn, R. Langer, M. M. Amiji, J. Controlled Release 2003, 86, 223.

[6] A. Akinc, D. M. Lynn, D. G. Anderson, R. Langer, J. Am. Chem. Soc. 2003, 125, 5316.

[7] D. G. Anderson, D. M. Lynn, R. Langer, Angew. Chem., Int. Ed. 2003, 42, 3153.

[8] A. Akinc, D. G. Anderson, D. M. Lynn, R. Langer, Bioconjugate Chem. 2003, 14, 979.

[9] D. G. Anderson, A. Akinc, N. Hossain, R. Langer, Mol. Ther. 2005, 11, 426.

[10] G. T.Zugates, W. Peng, A. Zumbuehl, S. Jhunjhunwala, Y. H. Huang, R. Langer, J. A. Sawicki, D. G. Anderson, Mol. Ther. 2007, 15, 1306.

[11] G. T. Zugates, N. C. Tedford, A. Zumbuehl, S. Jhunjhunwala, C. S. Kang, L. G. Griffith, D. A. Lauffenburger, R. Langer, D. G. Anderson, Bioconjugate Chem. 2007, 18, 1887.

[12] J. J. Green, G. T. Zugates, N. C. Tedford, Y.-H. Huang, L. G. Griffith, D. A. Lauffenburger, J. A. Sawicki, R. Langer, D. G. Anderson, Adv. Mater. 2007, 19, 2836.

[13] J. J. Green, B. Y. Zhou, M. M. Mitalipova, C. Beard, R. Langer, R. Jaenisch, D. G. Anderson, Nano Lett. 2008, 8, 3126.

[14] A. Akinc, A. Zumbuehl, M. Goldberg, E. S. Leshchiner, V. Busini, N. Hossain, S. A. Bacallado, D. N. Nguyen, J. Fuller, R. Alvarez, A. Borodovsky, T. Borland, R. Constien, A. de Fougerolles, J. R. Dorkin, K. Narayanannair Jayaprakash, M. Jayaraman, M. John, V. Koteliansky, M. Manoharan, L. Nechev, J. Qin, T. Racie, D. Raitcheva, K. G. Rajeev, D. W. Sah,
J. Soutschek, I. Toudjarska, H. P. Vornlocher, T. S. Zimmermann, R. Langer, D. G. Anderson, Nat. Biotechnol. 2008, 26, 561.

[15] M. Frank-Kamenetsky, A. Grefhorst, N. N. Anderson, T. S. Racie, B. Bramlage, A. Akinc, D. Butler, K. Charisse, R. Dorkin, Y. Fan, C. Gamba-Vitalo, P. Hadwiger, M. Jayaraman, M. John, K. Narayanannair Jayaprakash, M. Maier, L. Nechev, K. G. Rajeev, T. Read, I. Röhl, J. Soutschek, P. Tan, J. Wong, G. Wang, T. Zimmermann, A. de Fougerolles, H.-P. Vornlocher, R. Langer, D. G. Anderson, M. Manoharan, V. Koteliansky, J. D. Horton, K. Fitzgerald. Proceedings Natl. Acad. Sci. USA 2008, 105, 11915.

[16] R. U. Svensson, M. R. Shey, Z. K. Ballas, J. R. Dorkin, M. Goldberg, A. Akinc, R. Langer, D. G. Anderson, D. Bumcrot, M. D. Henry, Mol. Ther. 2008, 16, 1995.

[17] D. Grimm, K. L. Streetz, C. L. Jopling, T. A Storm, K. Pandey. C. R. Davis, P. Marion, F. Salazar, M. Kay, Nature 2006, 441, 537.

[18] M. John, R. Constien, A. Akinc, M. Goldberg, Y.-A. Moon, M. Spranger, P. Hadwiger, J. Soutschek, H.-P. Vornlocher, M. Manoharan, M. Stoffel, R. Langer, D. G. Anderson, J. D. Horton, V. Koteliansky, D. Bumcrot, Nature 2007, 449, 745 . 